\title{
Por uma educação significativa: uma abordagem fenomenológica do Programa Institucional de Bolsa de Iniciação à Docência - PIBID
}

\begin{abstract}
Resumo
O presente artigo analisa, através de uma perspectiva Husserliana, a relação entre os sujeitos (professor e aluno) que buscam o conhecimento e o mundo que doa sentido a esta intenção de conhecer. Este texto, deste modo, busca não só trazer uma caracterização teórica da fenomenologia de Edmund Husserl, mas também uma análise da relação professor-aluno no contexto educacional atual, bem como a experiência que o PIBID pode thes proporcionar.
\end{abstract}

Palavras-chave: Husserl. Fenomenologia. Educação.

\section{Elemar Kleber Favreto}

Universidade Estadual de

Roraima - UERR -

Boa Vista - Brasil

elemar@uerr.com.br

Rafael Parente Ferreira Dias

Universidade Estadual de

Roraima - UERR -

Boa Vista - Brasil

rafael.dias@uerr.edu.br

\section{Para citar este artigo:}

FAVRETO, Elemar Kleber; DIAS, Rafael Parente Ferreira. Por uma educação significativa: uma abordagem fenomenológica do Programa Institucional de Bolsa de Iniciação à Docência - PIBID. Revista Linhas. Florianópolis, v. 19, n. 39, p. 271-285, jan./abr. 2018. 
For a meaningful education: a phenomenological approach to PIBID, the - Institutional Scholarship Program for
Teaching Initiation

\begin{abstract}
The present article analyzes, from a Husserlian perspective, the relationship between the subjects (teacher and student) who seek knowledge and the world that gives meaning to this intention to know. This text, therefore, seeks not only to present a theoretical characterization of Edmund Husserl's phenomenology, but also an analysis of the teacherstudent relationship in the current educational context, as well as an overview of the experience that PIBID may provide.
\end{abstract}

Keywords: Husserl. Phenomenology. Education. 


\section{Introdução}

A fenomenologia, principalmente a husserliana, pauta-se basicamente num eu transcendental, um eu que não está no mundo, mas que é a própria possibilidade e emergência dele. Mundo só é o que é, para os fenomenólogos, porque existem estruturas subjetivas que o sustentam como tal. Tais estruturas se fundamentam, no caso de Edmund Husserl, num "eu puro" ou "eu transcendental”. Mas, como pensar este eu transcendental numa filosofia da educação ou numa experiência educacional? Este é o principal problema que se destaca neste texto. Neste sentido, tentaremos abordar a perspectiva da educação vista de um modo "relacional", em que não há nem a imposição de um conhecimento informativo e nem a busca por informações soltas e desprovidas de sentido; o que há é uma relação entre aqueles que buscam o conhecimento, mas que estão sempre em vista de um objeto pretendido. A educação, no sentido fenomenológico, é concebida como uma busca por um conhecimento que não está no professor e tampouco no aluno, mas na relação de ambos com o objeto de conhecimento. Assim, o conhecimento não é algo separado do humano, mas aquilo que faz com que o homem seja o que é, já que este só pode conhecer o mundo porque o interioriza, porque o toma como consciência, como algo próprio e particular. Não há, na fenomenologia, apenas um repasse de informações, como se o conhecimento fosse algo desprendido, solto, e o papel do homem fosse apenas "apanhá-lo". O conhecimento brota na medida em que o "criamos" (fazemos nascer), já que ele surge de uma discussão, de um diálogo entre o educador, o educando e o seu objeto de análise (uma relação entre sujeitos e objeto), ou ainda, surge como sentido criado por ambos numa única relação.

Acreditamos que a fenomenologia possa ter um papel importante na discussão dos métodos educacionais contemporâneos. Ela, de uma forma ou de outra, tenta nos trazer novamente ao estatuto do humano, à essência do homem, nos propondo uma busca da natureza constitutiva de nós mesmos.

A proposta deste texto é tentar retratar a educação numa perspectiva fenomenológica utilizando-se, para tanto, das experiências com o Programa Institucional de Bolsa de Iniciação à Docência (PIBID). Nesse sentido, num primeiro momento, 
buscaremos revisar a literatura de um dos fundadores da fenomenologia, Edmund Husserl, através de uma de suas obras mais emblemáticas, Meditações cartesianas. Nessa obra, o autor descreve as caracterizações mais fundamentais de sua fenomenologia, buscando em Descartes e Kant os princípios de uma filosofia fenomenológica. Além da obra husserliana, utilizaremos também alguns textos de Joel Martins (1992), que direciona o nosso entendimento aos pormenores da dimensão fenomenológica da educação.

Assim, este texto está dividido em três momentos: no primeiro, trataremos das principais caracterizações conceituais de Husserl acerca da sua filosofia, com base nas Meditações cartesianas e na análise feita por Joel Martins (1992); no segundo momento, analisaremos o texto husserliano, tentando desenvolver uma abordagem fenomenológica da educação, ou de como podemos compreender a filosofia husserliana dentro do contexto educacional; e, num terceiro momento, já como parte das considerações finais, buscaremos demonstrar como as experiências do PIBID podem ser significativas para os professores e alunos, de modo a serem reflexos da dimensão fenomenológica da educação.

\section{Husserl e a filosofia fenomenológica}

A filosofia de Husserl, como sabemos, está fundamentada numa fenomenologia, termo que designa um estudo e descrição dos fenômenos. Fenômeno, por sua vez, é um conceito que aparece, com maior claridade, na filosofia kantiana e serve para designar "aquilo que aparece para nós", ou seja, para Kant, os nossos sentidos não conseguem chegar realmente ao noumenon, "coisa em si" (ou como a coisa realmente é), mas apenas ao phainomenon", "aparência da coisa" (como a coisa aparece aos nossos sentidos). Husserl se apropria dessa conceituação e a desenvolve de tal forma a mostrar que a nossa consciência é criadora de mundo, isto é, que tudo o que está "posto diante de nós" (objeto) é um fenômeno de nossa consciência:

${ }^{1}$ Cf. CAYGILL, H. Dicionário Kant. Rio de Janeiro: Jorge Zahar Ed., 2000, p. 149. 
Se nos ativermos a simples fenomenologia do conhecimento, trata-se nela da essência do conhecimento, patenteável de modo directo e intuitivo, isto é, trata-se no âmbito da redução fenomenologia e da autopresentação, de uma patenteação intuitiva e separação analítica das múltiplas espécies de fenômenos, que a vasta rubrica de <conhecimento> abarca [...] As vivências cognitivas - e isto pertence à essência - têm uma intentio, visam (meinem) algo, referem-se, de um ou outro modo, a uma objectualidade. É próprio delas referir-se a uma objectualidade [...] (HUSSERL, [s.d.] p. 83)

Desta forma, não há uma busca pela verdade na coisa mesma (coisa em si, noumenon), mas uma busca pela verdade na relação das coisas com a nossa consciência, já que é necessário compreendermos isto que somos, para que possamos compreender o que é externo a nossa consciência:

Quando nos movemos na atitude fenomenológica, nos tornamos algo como observadores imparciais da cena que passa ou como espectadores de um jogo. Nós nos tornamos espectadores. Contemplamos os envolvimentos que temos com o mundo e com as coisas nele, e contemplamos o mundo em seu envolvimento humano. Não somos mais simplesmente participantes do mundo; contemplamos o que é ser um participante no mundo e nas manifestações. Mas as intencionalidades que contemplamos - as convicções, dúvidas, suspeições, certezas e percepções que examinamos e descrevemos - ainda são nossas intenções. (SOKOLOWSKI, 2004, p. 57)

Lançamo-nos, assim, num mundo de possibilidades, num mundo no qual tudo o que se mostra à percepção só aparece porque temos consciência do mundo e dos nossos próprios sentidos, entretanto, a fenomenologia de Husserl quer ir além, demonstrar a profundidade das essências:

Fenomenologia é o estudo das essências. Alguns indivíduos, ignorando o sentido de essência, afirmam que tal coisa não existe, que essência confunde-se com a idéia de alma e reportam-nos a Santo Tomás. Entretanto, embora tenha procurado definir as essências, como, por exemplo, a essência da percepção, a essência da consciência, a fenomenologia tal como a interpretamos substitui a essência pela existência e não pensamos que seja possível compreender o homem e o mundo de outra forma, senão a partir da sua "facticidade". (MARTINS, 1992, p. 51) 
A visão da essência é uma intuição originária passível de juízos predicativos verdadeiros. "[...] Ela é a visão do sentido ideal que atribuímos ao fato materialmente percebido e que nos permite identificá-Io." (DARTIGUES, 1992, p. 15). Ou seja, cada objeto está aberto à intencionalidade da consciência, nos seus infinitos sentidos e conexões, nenhum objeto deixará de ser o que é, ele permanecerá no seu ser primitivo, originário e constitutivo:

A fenomenologia quer ser ciência e método, a fim de elucidar possibilidades, possibilidades do conhecimento, possibilidades da valoração, e as elucidar a partir do seu fundamento essencial; são possibilidades universalmente em questão e, portanto, as investigações fenomenológicas são investigações universais de essências [...] (HUSSERL, [s.d.] p. 79)

A fenomenologia é esta busca pela descrição do mundo tal como ele se apresenta aos nossos sentidos, ou seja, como ele é em sua estrutura mais particular. Nesse sentido, devemos compreender, antes de tudo, um dos principais conceitos husserlianos, o conceito de epoché. Para Husserl, só podemos avançar num verdadeiro conhecimento se pudermos efetuar uma "redução fenomenológica" (epoché), ou seja, radicalizar ainda mais a dúvida cartesiana (dúvida hiperbólica), já que Descartes, segundo o filósofo alemão, ainda teria ficado preso a certos axiomas moldados pela geometria, estando, portanto, numa relação muito próxima com o próprio mundo. Para Husserl, devemos ultrapassar esta dúvida acerca das coisas e nos direcionar a uma dúvida transcendental, em que nada mais possa nos prender ao mundo, apenas um objetivo: o objetivo do conhecimento verdadeiro. Porém, este objetivo deve ser encarado como um projeto, pois não podemos ter uma certeza prévia nem mesmo de sua própria realização. É nesse sentido que nos perdemos em nossa consciência, já que o próprio mundo não é em si mesmo, sendo apenas “consciência de mundo”. E consciência não é nada sem um objeto, portanto, ter consciência é sempre ter consciência de..., isto é, ter consciência de algo que não é ela mesma:

[...] deseja-se [com a redução fenomenológica, ou epoché] encontrar exatamente que partes da experiência são verdadeiramente partes da nossa consciência, diferenciando-as daquelas que são simplesmente 
supostas. O propósito deste momento é isolar o objeto da consciência as coisas, as pessoas, as emoções ou outros aspectos que constituem a experiência que estamos tendo. (MARTINS, 1992, p. 59-60)

Perante esta concepção ainda fica uma questão: se o mundo e as coisas corpóreas, imaginadas, pensadas são apenas consciência de..., o que é este eu? Para melhor explicar isso é que devemos distinguir dois tipos de "eu" na filosofia husserliana: o "eu transcendental” e o "eu psicofísico". Há um eu da redução (eu puro) e um eu concreto, que já está implícito no próprio mundo. O eu psicofísico é o homem enquanto unidade corpórea e psicológica, ou seja, o homem como o julgamos ser - dotado de Pensamento, extensão e uma "união entre corpo e alma", como já descreveu Descartes em suas Meditações -, porém, este "eu”, de herança cartesiana, não é isto que nós mesmos somos, isto é, nossa "essência" humana é muito mais do que um simples eu concreto; o verdadeiro humano, segundo Husserl, reside no "eu transcendental", ou no "ego puro". O eu puro é aquele que possui uma "consciência pura"”2 acerca do mundo. Porém, para que possamos nos encontrar como eus puros precisamos realizar a epoché, realizar esta redução fenomenológica. O próprio Husserl (2001, p. 38) nos coloca diante desta perspectiva nas suas Meditações cartesianas:

Pode-se dizer assim que a $\varepsilon \pi \circ \chi \eta$ [epoché] é o método universal e radical pelo qual me percebo como eu puro, com a vida de consciência pura que me é própria, vida na qual e pela qual todo o mundo objetivo existe para mim, exatamente da forma como existe para mim.

\footnotetext{
${ }^{2}$ A consciência é uma intencionalidade, que quer dizer "consciência de algo". A intencionalidade é a capacidade que a consciência possui para transcender, para dirigir-se a algo outro que não a si mesma. Em Husserl, a consciência não é duplicação de um pensamento absoluto, mas, "projeto de mundo", voltado a um mundo que ela não abarca, mas em cuja direção ela segue. É reflexão que parte do Cogito e se orienta às coisas (do cogito ao intentio). Intenção, assim, é uma atividade, operação real que implica uma relação causal. Não é uma "relação interna" (psicológica), mas, envolve duas coisas: um conteúdo vivido e um objeto. A intencionalidade não se trata de uma influência da consciência sobre o objeto, não há uma intervenção, há apenas a pura doação de sentido. Ver um objeto não é reproduzi-lo na mente, é "visá-lo", é dar sentido. A consciência, desta forma, é doadora de sentido, ela abriga o objeto e é fonte de sentido do mesmo. A consciência dá sentido às coisas, portanto, há um processo de constituição, uma redescoberta de sentido no mundo; estamos, por isso, "condenados ao sentido": assim funciona a fenomenologia, confrontando perspectivas, confirmando percepções, descrevendo o sentido da coisa que aparece, da coisa que é phainomenon.
} 
O eu puro husserliano não é, assim, mais um sujeito que representa o mundo em sua consciência, mas a própria consciência deste é que constrói o mundo. O eu puro é, portanto, um "eu" que observa a si mesmo, que "percebe sua percepção percebendo", ou seja, é aquele que é consciente de si ao doar "sentido" ao mundo, ou ao ser o próprio “sentido" de mundo. Não há aqui, como em Descartes, uma representação do mundo exterior, o que há é um "ir às coisas mesmas”, ou melhor, à significação da coisa, já que esta significação é dada a partir da nossa própria consciência, e não através da "coisa em si”. Somos, acima de tudo, consciência das coisas, e não mais um sujeito, transformado em objeto, que está no mundo, um sujeito que só existe perante um objeto a ser conhecido; somos mais do que meros "homens concretos"; somos uma "subjetividade pura" que é o próprio sentido de mundo ser o que é.

Nesta perspectiva é que não há mais sujeito e nem objeto, tudo é consciência de um ego puro, no entanto, é nesta dissolução do sujeito e do objeto que o conhecimento, enquanto algo puramente transcendental se mostra e aparece em toda a sua extensão. 0 conhecimento não é, para a fenomenologia, outra coisa senão fenômeno de consciência, entretanto, este fenômeno não é algo que se encontra no mundo físico e material, mas numa dimensão transcendental, numa dimensão de possibilidades puras.

Perante este subjetivismo transcendental é que nos vemos, de certa forma, fora do mundo, já que através da epoché nos distanciamos cada vez mais dele, no entanto, é este estar fora do mundo que nos possibilita estarmos dentro dele, pois é por meio desse afastamento transcendental que podemos compreender a própria possibilidade de mundo que se mostra da forma que se mostra, tal como se apresenta - em sua perseidade essencial. A seguir, apresentamos uma importante citação para corroborar nosso ponto de vista: “O novo método de reflexão filosófica chamar-se-á redução fenomenológica porque reduz todo o ser à sua pureza do ser-fenômeno e fará passar todo o conhecimento perante o tribunal da evidência do cogito" (KELKEL; SCHÉRER, 1982, p. 38).

Não poderíamos pensar um objeto qualquer se não houvesse uma estrutura que nos possibilitasse pensá-lo; este subjetivismo, este eu transcendental não é o sujeito que observa o objeto (e muito menos o objeto observado pelo sujeito), o eu transcendental é a própria relação do sujeito com o objeto, é o campo que se abre a partir da visão do sujeito ao objeto visado, é a própria possibilidade de emergência de mundo. 


\section{A fenomenologia husserliana numa perspectiva educacional}

Cremos que a melhor forma de relacionarmos a educação com a fenomenologia husserliana é através da sua perspectiva crítica e reflexiva, ou melhor, através da perspectiva de uma consciência da realidade que nos cerca. O mundo não é meramente o objeto ou mesmo o sujeito, mas, essencialmente, o sentido que se encontra entre ambos. Se assim o mundo for pensado, o veremos com outros olhos, sob o prisma de um conhecimento intencional, em que toda a subjetivação e objetivação se desvanecem, permanecendo este conhecimento que se estabelece na relação sujeito/objeto. O ser humano abre-se para a dimensão do "possível", a educação transforma-se em uma fenomenologia genética e constitutiva do próprio sujeito. Josgrilberg esclarece essa interface entre educação e fenomenologia:

A experiência da educação nos abre a percepção de um ser humano que se desenvolve educando-se. A experiência da educação nos remete de imediato à fenomenologia genética que revela a constituição do ser humano em sua formação no tempo. O ser humano revela suas características essenciais em formação. O ser humano está sendo. A educação aparece na base da antropogenética. (JOSGRILBERG, 2015, p. 9)

Desta forma, não há mais um conhecimento pronto e acabado que possa ser repassado, como se fosse algo solto, separado disto que somos e das vivências que nos constituem; o que há é uma construção, um conhecimento que será edificado através da relação professor/aluno/objeto, ou melhor, através da experimentação com o mundo, das vivências da consciência. Não é mais um conhecimento construído unicamente pelo professor e repassado ao aluno, mas arquitetado por ambos na sua relação e vivência com o mundo. Trata-se de uma dinâmica dialeticamente constituída, como nos mostra Josgrilberg (2015, p. 10):

A educação, por outro lado, mostra em seu conteúdo que o compartilhamento é uma dinâmica de "formação". A educação trabalha com o modo de ser humano e com formas de vida que esse modo de ser humano assume concretamente. A ideia de formação é uma ideia que está presente continuamente onde o compartilhamento adquire ou sedimenta condições de sentido. Os indivíduos e os grupos de indivíduos 
estão posicionados para a formação e a educação exige essa abertura entre os envolvidos. O ser humano é, em uma de suas dimensões originárias, "a abertura para ser educado".

Ambos, educador e aluno, neste sentido, deparam-se com um mesmo desafio, já que o conhecimento é criado na medida em que ambos dão sentido às coisas que lhes aparecem, e este sentido não deixa de ser, em última instância, problemático e dialético. Problemático porque todo conhecimento envolve a resolução de um problema, e tal resolução suscita novos problemas. Dialético porque será um conhecimento construído através de um diálogo duplo: o diálogo sujeito/mundo e o diálogo professor/aluno.

Se o sentido é, de certa forma, problemático e dialético, a aprendizagem se dá nos dois polos, tanto para o aluno, quanto para o próprio professor. Desta maneira, ambos procurarão compreender o mundo de uma forma conjunta, isto é, ambos darão sentido a ele juntos, tendo consciência dele, mas expressando cada vivência (conhecimento) de maneira distinta e singular. Isto é, o mundo é construído ${ }^{3}$ dialeticamente, mas compreendido individualmente. E esta é a maneira que gostamos de pensar a educação, já que não se pode dizer que o professor é o único detentor do saber, pelo contrário, ele também se encontra neste estágio de vivência intencional, neste caminho sempre a ser percorrido, que é, em seu sentido pleno, transcendental. Ademais, Kelkel e Schérer admitem que cada ramo do conhecimento possui dimensões inexploradas, campos semióticos próprios, os quais só serão devidamente explorados através de uma consciência intencional dirigida a este objeto específico. Nesse sentido, a Matemática, a Química, e todas as demais áreas do saber transformam-se em verdadeiros laboratórios de análises fenomenológicas, como podemos observar na citação que segue:

\footnotetext{
3 O termo "construído", colocado várias vezes no texto, pode ser facilmente confundido com o construtivismo piagetiano. Claro que podemos facilmente fazer uma relação entre o construtivismo e a fenomenologia, no entanto, não podemos perder de vista a nossa perspectiva transcendental; para Piaget e Emilia Ferreiro todo o conhecimento é construído, e ele está sempre em vista de uma ação com..., entretanto, esta ação com já pressupõe o mundo, já há sentido na ação, no agir sobre a coisa, sobre o objeto. Para a fenomenologia husserliana isso não ocorre, não há sentido prévio, o sujeito em si mesmo não possui um sentido sem o objeto a ser visado, e o objeto em si mesmo também não possui significação própria; tudo é relacional, todo o sentido, todo o conhecimento é uma relação sujeito/objeto. Sentido, neste caso, é aquilo que se forma transcendentalmente na relação. O “eu puro", portanto, não é o sujeito, mas aquilo que transcende ao próprio mundo, como se estivesse observando de fora toda a relação que este sujeito tem com o objeto em questão.
} 
A ciência é uma obra espiritual do homem que pressupõe como ponto de partida, historicamente e também para quem quer que a estude, 0 mundo ambiente da vida, mundo da intuição universalmente pré-dada como existente; mas, além disso, na sua aplicação e no seu desenvolvimento, a ciência pressupõe também continuamente este mundo ambiente enquanto se dá ao sábio a cada instante. Para o físico, por exemplo, é o mundo no qual ele vê os seus instrumentos de medida, ouve as batidas do metrônomo, avalia grandezas percepcionais, etc., é este mundo no qual, para mais, ele se sabe a si mesmo compreendido com toda a sua actividade e todos os seus pensamentos teóricos. (KELKEL; SCHÉRER, 1982, p. 103)

Percebe-se uma vez mais que o conhecimento, na perspectiva fenomenológica, é pura construção dialógica entre um sujeito que anela pelo saber e um objeto com condições empíricas de ser explorado, portanto:

O pesquisador estará, aliás, tanto mais consciente do caráter significante do objeto quanto menos desvendada ainda estiver essa significação; o objeto se propõe a ele como um enigma, isto é, como uma questão dirigida ao autor ausente que deixou sobre sua obra o vestígio de uma intenção desaparecida: o que quis ele fazer? O que quis ele dizer? (DARTIGUES, 1992, p. 50)

Para encontrar o caráter significante do objeto de estudo, o aluno ou pesquisador necessitará de "Reflexão" e "sentido", duas palavras fundamentais dentro da perspectiva fenomenológica da educação. Analisando-as especificamente no cotidiano em sala de aula, é notória a falta de ambas por parte dos alunos; não há um real desejo pelo saber, uma autêntica intenção fenomenológica dirigida ao conhecimento, o que favorece e muito a falta de reflexão, uma vez que, como já foi demonstrado acima, sem intencionalidade não há possibilidade de emergência do conhecimento, pois para que este se dê necessita-se de um objeto intencionalmente refletido - a instância transcendental - sem a qual se torna impossível, numa perspectiva fenomenológica, a construção do saber.

Diante de tal panorama educacional surge à seguinte questão: afinal, o que queremos com a educação? Alunos passivos que reproduzem um conhecimento sem prévia reflexão ou alunos que, em conjunto com o professor, transformem o conhecimento em um momento dialético e transcendental, uma construção dinâmica, 
alternada, ativa e duplamente eficiente, uma vez que educador e aluno, em uníssono, ampliam suas visões cognitivas, alcançando não apenas o conhecimento, mas também o sentido do mesmo.

Ora, a resposta fenomenológica para essa questão não poderia ser outra senão que, no primeiro exemplo, temos um aluno sem preocupação cognitiva, talvez sua única meta em sala de aula seja conseguir um diploma, não tendo interesse no saber em si mesmo, desconhecendo o fascínio pela ciência. E, nessas condições, torna-se incapaz de descobrir o verdadeiro sentido da educação, bem como o prazer intelectual que dela emerge. Por outro lado, o segundo exemplo encaixa-se mais adequadamente sob os moldes fenomenológicos da educação. Por conseguinte, o homem, segundo a fenomenologia, é o produto de suas vivências, melhor ainda, é o resultado da relação intencional que emerge a partir de seu contato com o "mundo da vida", e a educação é apenas mais um destes momentos; refletir sobre as bases educacionais e seus fundamentos é essencial para uma visão crítica da realidade, para a construção de um indivíduo consciente do seu papel como criador de sentido. Ademais, é dentro das Instituições de Ensino que o pensamento dialético encontra o terreno mais profícuo para o seu livre desenvolvimento, sendo assim, proporcionar ao estudante condições para que, por si mesmo, alcance as “intuições das essências" é fundamental para o seu avanço intelectual e também do próprio professor, como já foi demonstrado acima. De fato, o aluno pretendido pelo pensamento fenomenológico é aquele que está além do simples convencionalismo educacional, não aceita ser um reprodutor social, dispensa a educação passiva, não refletida; ao contrário, a postura fenomenológica exige reflexão em todos os campos da vida, sobretudo em sala de aula, onde é possível perceber, por meio da intuição, a magnitude do conhecimento transcendental, e, como moeda de troca, é também possível conseguir captar o que anteriormente estava velado, o verdadeiro sentido da educação.

Pensando nestes termos, podemos dizer que a experiência que o Programa Institucional de Bolsa de Iniciação à Docência (PIBID) pode proporcionar ao professor e ao aluno pode ser equiparada a essa postura fenomenológica acima descrita, já que toda a educação que tenha uma perspectiva fenomenológica traz certa atitude crítica perante a realidade em que o homem está inserido. 


\section{Considerações finais: o PIBID como experiência fenomenológica de ensino}

Vimos até aqui como a fenomenologia husserliana está estruturada, onde a redução fenomenológica desempenha um papel importante para a descrição de essências, principal papel de uma análise fenomenológica da realidade. Descrever as essências é produzir conhecimento, já que o homem se encontrará no limiar do mundo, onde brota o sentido das coisas. O aspecto transcendental desta filosofia é o que a diferencia de todas as outras perspectivas filosóficas, já que o transcendente é aquilo que está fora do mundo e o imanente o que se encontra em seu interior, por outro lado, o transcendental é aquilo que se encontra entre o transcendente e o imanente, entre o que é parte do mundo e o que está fora dele, portanto pensar transcendentalmente já nos remete ao limite do mundo. Para tanto, se faz necessário que o homem esteja disposto a se questionar e refletir sobre a vida e sobre as coisas que fazem parte de seu campo de atuação no mundo.

A educação, vista desta maneira fenomenológica, desempenha um papel importantíssimo na construção do humano, já que é através dela que o homem poderá compreender a estrutura que sustenta o sentido das coisas, na medida em que passa a compreender a sua própria essência humana. Educar não é impor, não é oprimir, não é unicamente repassar valores e informações; educar é, acima de tudo, facilitar o processo de "criação", ou seja, facilitar o processo de construção de sentido e conhecimento pelo educando. E, além disso, educar também é sempre aprender, pois, como já foi dito anteriormente, o conhecimento é sempre uma "criação" problemática e dialética. Assim, buscamos nas experiências do PIBID esse modo próprio de expressar a vivência dos alunos em sala de aula e do modo próprio que eles podem encontrar e criar o sentido para o mundo em que estão se inserindo.

O programa disponibiliza aos alunos e professores nele envolvidos uma abertura para um mundo de possibilidades antes ignoradas. Um exemplo disso foi o Subprojeto Interdisciplinar do PIBID da Universidade Estadual de Roraima (UERR). O subprojeto envolveu dois coordenadores de área, quatro supervisores, vinte e quatro acadêmicos e mais de dois mil alunos em duas escolas de Boa Vista - Roraima. Ele foi desenvolvido de modo a compreender melhor o papel da educação política na formação do cidadão, envolvendo com quatro disciplinas distintas: Filosofia, História, Sociologia e Geografia. 
O subprojeto proporciona uma experiência única aos seus envolvidos, pois os professores, acadêmicos e alunos conseguiram demonstrar que as experiências vivenciadas foram realmente significativas para a sua formação. O subprojeto, num primeiro momento, proporcionou aos acadêmicos um contato com as escolas, os alunos e os professores, quando buscaram vivenciar o meio escolar, sempre relatando as suas experiências em um diário de campo. Posteriormente, foram desenvolvidos estudos individuais e em grupo sobre os principais documentos que estruturam a escola, seguidos de um relato dos principais mecanismos políticos existentes nesses documentos. Em seguida, os professores, acadêmicos e alunos se envolveram com as atividades práticas do subprojeto, apresentando as principais relações entre a política, as políticas públicas e a cidadania em oficinas, minicursos, grupos de estudos e exposições culturais oferecidos na universidade e nas escolas.

O que pudemos perceber com o desenvolvimento dessas atividades foi 0 crescimento de uma consciência cidadã dos alunos, acadêmicos e professores envolvidos no subprojeto. Julgamos, desse modo, que essa vivência foi essencial para o desenvolvimento reflexivo dos envolvidos, demonstrando que o programa tem um potencial muito grande para o desenvolvimento humano e profissional dos participantes. Podemos dizer que os acadêmicos, principal público-alvo do programa, tiveram um rendimento acadêmico muito melhor em sala de aula, já que tiveram uma mudança de postura, de passiva e dispersiva para ativa e reflexiva.

Podemos dizer, portanto, que pensar o mundo de uma forma transcendental é pensá-lo na sua mais íntima estruturação. Não somos parte do mundo, senão o próprio mundo, pois o criamos ao darmos sentido às coisas. Estamos convictos que o Subprojeto Interdisciplinar do PIBID/UERR foi uma experiência de extrema importância e significação para todos os envolvidos, rendendo não só produtos acadêmicos e escolares, mas também uma reflexão sobre o que nos torna cidadãos e, acima de tudo, humanos. 


\section{Referências}

CAYGILL, Howard. Dicionário Kant. Tradução de Álvaro Cabral. Rio de Janeiro: Jorge Zahar Ed., 2000.

DARTIGUES, André. O que é fenomenologia? Tradução de Maria José J. G. de Almeida. São Paulo: Editora Moraes, 1992.

HUSSERL, Edmund. A ideia da fenomenologia. Tradução de Artur Morão. Lisboa: Edições 70, [s.d.].

HUSSERL, Edmund. Ideas relativas a una fenomenología pura y una filosofia

fenomenológica. Tradução de José Gaos. México: Fondo de Cultura Económica, 1997.

HUSSERL, Edmund. Meditações cartesianas: introdução à fenomenologia. Tradução.

Frank de Oliveira. Lisboa: Madras, 2001.

HUSSERL, Edmund. Primeiro Grau da consideração fenomenológica. In: HUSSERL, Edmund. A ideia da Fenomenologia. Trad. Artur Morão. Lisboa: Madras, 2001.

JOSGRILBERG, Rui. Fenomenologia e educação. São Paulo/Porto. Ano. XVIII, n.

38, maio/ago., 2015. Disponível em: <http://www.hottopos.com/notand38/05-14Rui.pdf>. Acessado em: 15/08/2016.

KELKEL, Arion; SCHÉRER, René. Husserl. Lisboa: Edições 70, 1982.

MARTINS, Joel. Estudos sobre existencialismo, fenomenologia e educação. São Paulo: Moraes, 1983.

MARTINS, Joel. Um enfoque fenomenológico do currículo: educação como poiésis. São Paulo: Cortez, 1992.

SOKOLOWSKI, Robert. Introdução à fenomenologia. Tradução de Alfredo de Oliveira Moraes. São Paulo: Edições Loyola, 2004. 